\title{
UPAYA PENANGANAN GANGGUAN AKTIVITAS PADA PENDERITA GAGAL JANTUNG SELAMA MASA PANDEMI COVID-19
}

\author{
Felicia Risca Ryandini ${ }^{1 *}$, Laura K. Noviyanti ${ }^{2}$ \\ 1,2 Program Studi S1 Keperawatan, STIKES Telogorejo Semarang \\ *felicia_riska@stikestelogorejo.ac.id
}

\begin{abstract}
Abstrak
Masa Pandemi Covid 19 berdampak bagi kehidupan manusia salah satunya bagi penderita penyakit gagal jantung dalam manajemen perawatan diri. Gangguan aktivitas yaitu fatigue merupakan tanda dan gejala yang sering dirasakan dan akan mempengaruhi kualitas hidup pasien. Penelitian ini bertujuan untuk mengetahui efektivitas progressive muscle relaxation (PMR) terhadap fatigue pada gagal jantung. Penelitian ini menggunakan Quasi-Eksperimental Design dengan Randomized Kontrol Group Pretest-Posttest Design. Pemilihan sampel dilakukan dengan teknik Probability Sampling yaitu Simple random sampling. Alat ukur yang digunakan adalah kuesioner Fatique Assessment Scale (FAS). Uji statistik menggunakan uji $\mathrm{t}$ dependen dan uji $\mathrm{t}$ independen. Hasil penelitian didapatkan bahwa ada perbedaan yang signifikan antara nilai fatigue responden sebelum dan setelah diberikan intervensi ( $p$ value 0.0001) dan tidak terdapat perbedaan yang signifikan anatar nilai fatigue sebelum dan sesudah intervensi pada kelompok kontrol ( $p$ value 0.621). Hasil uji statistik antar kelompok didapatkan nilai $p$ value 0.0001 sehingga disimpulkan bahwa ada perbedaan yang signifikan antara rata-rata nilai fatigue responden pada kelompok intervensi dan kontrol. Hasil penelitian ini menunjukkan bahwa PMR efektif untuk mengatasi masalah fatigue pada penderita gagal jantung. Saran bagi peneliti selanjutnya perlu dikembangkan metode dengan dengan pendekatan fisik (PMR) dan emosional (psikis) untuk meningkatkan kapasitas fisik bagi penderita gagal jantung.
\end{abstract}

Keywords: gagal jantung, fatigue, progressive muscle relaxation

\begin{abstract}
Efforts to Manage Activity Disturbances in Heart Failure Patients During Covid-19 Pandemic. The Covid 19 pandemic period has had various impacts on human life, one of which is for heart failure patient in carrying out self-care management. Activity intolerance called fatigue, is a sign and symptom that is most often felt and affect the quality of life. This study aimed to determine the effectiveness of progressive muscle relaxation (PMR) on fatigue in heart failure. This study used a Quasi-Experimental Design with a Randomized Control Group Pretest-Posttest Design. The participants selection by simple random sampling. Data were collected using the Fatique Assessment Scale (FAS) questionnaire. Data were analyzed using Dependent T-Test and Independent T-Test. The results showed that there was a significant difference between the fatigue value of respondents before and after being given intervention ( $p$ value 0.0001) and there was no significant difference between the fatigue value before and after the intervention in the control group ( $p$ value 0.621). The results of statistical tests between groups obtained a $p$ value of 0.0001, so it was concluded that there was a significant difference between the average value of fatigue of respondents in the intervention and control groups. The results of this study indicate that PMR is effective in overcoming the problem of fatigue in people with heart failure. Suggestions for
\end{abstract}


future researchers need to develop methods with physical (PMR) and emotional approaches to increase the physical capacity of people with heart failure.

Keywords: fatigue, heart failure, progressive muscle relaxation

\section{PENDAHULUAN}

Tubuh kita merupakan gabungan dari beberapa sistem organ yang sangat kompleks yang masing-masing memiliki fungsinya sendiri. Salah satu yang memiliki peran penting di dalamnya adalah sistem kardiovaskular. Hasil Riset Kesehatan Dasar (RISKESDAS) Kemenkes RI tahun 2013, prevalensi penyakit jantung dari total penduduk berusia di atas 18 tahun didapatkan penyakit jantung koroner di Indonesia mencapai $0,5 \%$ dan gagal jantung sebesar 0,13\%. Kondisi ini tentunya akan menjadi perhatian sekaligus tantangan bagi tenaga kesehatan dalam memberikan pelayanan dan melakukan program pencegahan. Perawat yang dalam hal ini merupakan ujung tombak bagi perawatan pasien memiliki peran yang besar di dalamnya.

Banyaknya tanda dan gejala yang muncul pada penderita penyakit jantung tentunya akan membawa dampak bagi aktivitas sehari-harinya. Salah satu gejala atau prognosis yang sering dirasakan pasien adalah adanya fatigue (kelelahan). Data berdasarkan keluhan pasien yang dirawat inap di suatu Rumah Sakit bahwa sebesar $72 \%$ pasien dengan penyakit jantung mengalami kelelahan. Dari kelompok tersebut ditemukan bahwa semuanya pernah mengalami kelelahan di rumah dan $86 \%$ diantaranya mengatakan bahwa kondisi tersebut adalah hal yang paling mengganggu aktivitas sehari-hari (Grossman \& Brown, 2009; Jugdutt, 2012; Lewis, 2010).

Hal ini akan berpengaruh terhadap kualitas hidupnya. Berbagai upaya pencegahan saat ini dirasa kurang efektif mengingat bahwa kebutuhan pasien berbeda-beda walaupun dengan keluhan yang sama. Oleh karena itu diperlukan suatu strategi dalam upaya peningkatan kesehatan khususnya pada gangguan aktivitas pada pasien dengan penyakit jantung. Terdapat beberapa strategi untuk menurunkan status kelelahan antara lain dengan pendekatan latihan/ aktivitas, strategi perilaku, dukungan nutrisi, pendekatan fisiologis, dan pendekatan psikologis (Purwanto, 2013; Richmood, 2009).

Beberapa strategi untuk menurunkan fatigue antara lain exercise, strategi perilaku, dukungan nutrisi, dan pendekatan fisiologis. Salah satu strategi perilaku adalah progressive muscle relaxation yang merupakan terapi perilaku. Relaksasi otot progresif adalah suatu metode relaksasi melalui dua proses yaitu menegangkan dan merilekskan otot tubuh. Latihan ini adalah salah satu dari yang paling sederhana dan mudah dipelajari (Richmood, 2009). Tujuan dari latihan ini adalah untuk menurunkan tegangan fisik, menurunkan nadi dan tekanan darah dan respirasi. Berdasarkan penulisan yang dilakukan oleh Wilk and Turtoski (2001), progressive muscle relaxation merupakan salah satu pendekatan metode manajemen stress yang membawa keuntungan pada berbagai kasus yang termasuk dalam rehabilitasi pasien gangguan kardiovaskuler.

Teknik relaksasi otot progresif adalah memusatkan perhatian pada suatu aktifitas otot, dengan mengidentifikasi otot yang tegang kemudian menurunkan ketegangan dengan melakukan teknik relaksasi untuk mendapakan perasaan relaks (Purwanto, 2013). Relaksasi mengakibatkan renggangan pada arteri akibatnya terjadi vasodilatasi pada arteri \& vena oleh pusat vasomotor, salah 
satunya yaitu reflek baroreseptor. Aliran darah sistemik menjadi lancer, denyut nadi menjadi normal, frekuensi pernapasan menjadi normal, dan mengurangi evaporasi sehingga pasien menjadi nyaman dan tenang. Hal ini diakibatkan dari penurunan Reticullar Activating System (RAS) dan peningkatan aktivitas batang otak, sehingga dapat mengurangi gejala fatigue. Berlatarbelakang dari hal tersebut, melalui penelitian ini penulis ingin mengetahui efektivitas progressive muscle relaxation terhadap tingkat fatigue pada pasien gagal jantung dalam upaya manajemen perawatan diri selama masa Pandemi Covid 19.

\section{Metode}

\begin{tabular}{ccc}
\multicolumn{2}{c}{ Penelitian ini merupakan } \\
penelitian dengan melakukan
\end{tabular} eksperimen yang sesuai dengan tujuan penelitian untuk melihat ada tidaknya pengaruh variabel independen yaitu progressive muscle relaxation terhadap variabel dependen yaitu pengontrolan tingkat fatigue. Penelitian ini menggunakan Quasi-Eksperimental Design dengan Randomized Control Group Pretest-Posttest Design.

Sampel dalam penelitian ini adalah klien yang memenuhi kriteria sebagai berikut: usia 18 tahun ke atas, fungsional class NYHA II-III, efection fraction < 40\%, orientasi dan fungsi kognitif baik; dan kriteria eklsklusi: memiliki keterbatasan fisik (kecacatan), terdapat gangguan psikis, dan terdapat defisit neurologi.

Pada penelitian ini pengambilan sampel dilakukan dengan teknik Probability Sampling yang merupakan pemilihan sampel yang dilakukan secara acak. Metode yang digunakan adalah Simple random sampling. Peneliti membagi sampel menjadi dua kelompok yaitu kelompok perlakuan dan kelompok kontrol. Sebelum dilakukan intervensi, responden dilakukan pengukuran tingkat gangguan aktivitas responden tahap awal (pre test) dengan menggunakan kuesioner Fatique Assessment Scale (FAS). Pemberian strategi upaya kesehatan menggunakan standar operasional prosedur berupa: strategi perilaku progressive muscle relaxation, dan setelah dilakukan intervensi selama 30 hari dilakukan pengukuran tingkat fatigue kembali. Penelitian ini dilakukan di Puskesmas Karangayu dan Wilayah Binaan Kelurahan Karangayu, Semarang selama bulan Juli- Agustus 2020.

Tahap analisa data dibagi menjadi analisa data univariat dan bivariat. Analisis bivariat yang digunakan pada penelitian ini adalaha uji $t$ dependen untuk melihat tingkat fatigue sebelum dan setelah intervensi pada kelompok intervensi, dan tingkat fatigue awal dan akhir pada kelompok kontrol. Sedangkan uji $\mathrm{t}$ independen untuk melihat selisih tingkat fatigue pada pengukuran awal dan akhir pada kelompok.

\section{Hasil}

Penelitian ini dilaksanakan dalam tiga tahapan, antara lain pengambilan data pre test; pemberian intervensi dalam hal ini adalah mengajarkan strategi perilaku dengan teknik progressive muscle relaxation dan yang terakhir adalah data post test. 


\section{Distribusi Responden Menurut Usia, Jenis Kelamin, Pendidikan dan Sosial Ekonomi Pada Pasien Penyakit Jantung \\ Tahun $2020(n=120)$}

\begin{tabular}{ccc}
\hline Variabel & Jumlah & Persentase (\%) \\
\hline Usia & & \\
\hline Produktif & 92 & 76.7 \\
Tidak Produktif & 28 & 23.3 \\
\hline Jenis Kelamin & & 72.5 \\
\hline Laki-laki & 87 & 27.5 \\
Perempuan & 33 & \\
\hline Pendidikan & & 18.3 \\
\hline Dasar & 22 & 68.3 \\
Menengah & 82 & 13.3 \\
Tinggi & 16 & 79.2 \\
\hline Sosial Ekonomi & & 12.5 \\
\hline Baik & 95 & 100 \\
Kurang & 15 &
\end{tabular}

Tabel 2

Distribusi Rata-Rata Fatigue Sebelum dan Sesudah Intervensi Pada Kelompok Kontrol dan Intervensi Pada Pasien dengan Penyakit Jantung Tahun 2020

\begin{tabular}{lllllr}
\hline Variabel & Mean & SD & SE & $\begin{array}{c}\text { P } \\
\text { value }\end{array}$ & N \\
\hline Fatigue & & & & & \\
\hline Kel. Intervensi & & & & & \\
\hline Sebelum & 23.2 & 5.187 & 0.457 & 0.0001 & \\
Sesudah & 13.3 & 3.797 & 0.117 & & 60 \\
\hline Kel. Kontrol & & & & 0.0621 & \\
\hline Sebelum & 37.6 & 3.132 & 0.118 & & \\
Sesudah & 21.5 & 3.076 & 0.237 & & \\
\hline
\end{tabular}

Tabel 3

Distribusi Rata-Rata Fatigue Pada Kelompok Kontrol dan Intervensi Pada Pasien dengan Penyakit Jantung

Tahun 2020

\begin{tabular}{lccccc}
\hline \multicolumn{1}{c}{ Variabel } & Mean & SD & SE & $\begin{array}{c}\text { P } \\
\text { value }\end{array}$ & N \\
\hline $\begin{array}{l}\text { Kel. } \\
\text { Intervensi }\end{array}$ & 34.65 & 3.416 & 0.130 & & \\
Kel. Kontrol & 28.05 & 3.035 & 0.149 & 0.0001 & 120 \\
\hline
\end{tabular}

Tabel 1. menunjukkan bahwa responden yang didapatkan sebagian besar berusia produktif sebanyak 92 orang $(76.7 \%)$ dan sisanya non produktif yaitu lebih dari 64 tahun (23.3\%). Sesuai dengan angka kejadian yang sering terjadi, responden laki-laki didapatkan lebih banyak daripada perempuan yaitu sebesar 72.5\%. Rumah sakit yang digunakan peneliti merupakan rumah 
sakit negeri dengan karakteristik pendidikan responden paling banyak yaitu dengan pendidikan menengah setara SMA sebesar $68.3 \%$ dan pendidikan tinggi setaraf perguruan tinggi sebesar 13.3\%. Hal ini juga nampak pada status sosial ekonomi.

Tabel 2 menunjukkan bahwa hasil penelitian didapatkan bahwa rata-rata nilai fatigue responden pada kelompok intervensi sebelum diberikan perlakuan adalah 23.2 dengan standar deviasi 5.187. Terlihat nilai mean perbedaan setelah intervensi pada kelompok intervensi adalah 13.3 dengan standar deviasi 3.797. Hasil uji statistik didapatkan nilai $\mathrm{p}=0.0001$ maka dapat disimpulkan bahwa ada perbedaan yang signifikan antara nilai fatigue responden sebelum dan setelah diberikan intervensi. Pada uji bivariat untuk kelompok kontrol, didapatkan bahwa nilai $p$ value $=0.621$ maka dapat disimpulkan bahwa tidak terdapat perbedaan yang signifikan anatar nilai fatigue sebelum dan sesudah intervensi pada kelompok kontrol.

Tabel 3 menunjukkan bahwa hasil penelitian didapatkan bahwa rata-rata nilai fatigue kelompok intervensi adalah 34.65 dengan standar deviasi 3.416, sedangkan untuk kelompok kontrol ratarata bilai fatigue adalah 28.005 dengan standar deviasi 3.035. Hasil uji statistik didapatkan nilai $\mathrm{p}$ value $=0.0001$ dengan kesimpulan bahwa ada perbedaan yang signifikan antara rata-rata nilai fatigue responden pada kelompok intervensi dan kontrol.

\section{Pembahasan}

Aktivitas fisik yang berlebihan pada pasien dengan gagal jantung akan menimbulkan kelelahan atau fatigue. Pada masa pandemi ini, penderita gagal jantung mengalami suatu permasalahan di mana mereka merasa takut dan enggan untuk menjalani kontrol rutin di fasilitas kesehatan. Hasil penelitian sebelumnya (DeFilippis et al., 2020) mengungkapkan bahwa penderita penyakit kronis antara lain penyakit gagal jantung, gagal ginjal, kanker, dan diabetes mellitus mengalami penurunan angka kunjungan dalam kontrol rutin selama masa pandemin ini. Berbagai upaya yang sudah dilakukan salah satunya dengan telemedicine ternyata belum memberikan dampak yang baik bagi manajemen perawatan yang dilakukan pasien selama di rumah. Dalam artikel berjudul The impact of COVID-19 on heart failure hospitalization and management dikatakan bahwa pasien dengan penyakit gagal jantung yang menjalani perawatan mandiri di rumah banyak yang mengalami penurunan kondisi salah satunya adalah mengalami gangguan aktivitas, hal ini dikarenakan mereka takut untuk datang ke rumah sakit, jam pelayanan rawat jalan menurun, adanya pembatasan jumlah pasien rawat jalan karena social distancing dan beberapa rumah sakit tidak membuka unit pelayanan rawat jalan (Bromage et al., 2020).

Gangguan aktivitas yang paling sering dirasakan oleh penderita gagal jantung selama masa Pandemi Covid 19 ini adalah fatigue, adanya fatigue dikarenakan terjadi akibat curah jantung yang berkurang yang dapat menghambat sirkulasi normal dan suplai oksigen ke jaringan dan menghambat pembuangan sisa hasil metabolisme, juga terjadi akibat peningkatan energi yang digunakan untuk bernafas (Reza et al., 2020). Fatigue merupakan permasalahan fisik maupun psikologis yang ditemukan pada pasien gagal jantung. Fatigue digambarkan sebagai ketidakmampuan melakukan atau meyelesaikan rutinitas aktivitas sehari-hari atau membutuhkan waktu yang lama untuk melakukannya (Udjianti 2013). Manifestasi fatigue adalah penurunan kapasitas fisik maupun psikis dalam melakukan aktivitas atau kegiatan sehari-hari. 
Perasaan tidak berdaya merupakan salah satu manifestasi yang memperburuk pasien dengan penyakit jantung secara psikologis. Faktor yang berhubungan dengan fatigue adalah faktor fisik, psikologis dan lingkungan. Perubahan neurohormonal, dan aktivitas mediator inflamasi merupakan bagian dari faktor fisik. Depresi, stress dan kecemasan merupakan faktor psikis fatigue. Dukungan sosial dan dukungan keluarga menjadi faktor lingkungan yang berkaitan dengan fatigue (Kessing, 2015).

Pada penderita gagal jantung manajemen efektif perlu dilakukan selama perawatan baik saat di rumah sakit maupun saat menjalani perawatan mandiri di rumah, karena penanganan yang diberikan sifatnya adalah jangka panjang. Untuk itu diperlukan beberapa startegi dan upaya yang dapat mendukung perawatan penderita penyakit jantung dalam rangka meningkatkan kualitas hidup nantinya. Upaya tersebut dapat dilakukan untuk meningkatkan kapasitas fisik dan tidak dapat dipisahkan juga perlunya suatu upaya pelaksanaan dengan pendekatan secara fisik dan psikis.

Strategi perilaku yang dilakukan oleh peneliti untuk menangani masalah kelelahan pada responden adalah dengan teknik Progressive Muscle Relaxation (PMR). PMR itu sendiri merupakan suatu bentuk latihan relaksasi dengan gerakan mengencangkan dan melemaskan otototot pada suatu bagian tubuh pada satu waktu, untuk memberikan perasaan relaksasi secara fisik (Care, 2016). Kondisi relaksasi secara fisik dapat berpengaruh terhadap penurunan stres, kecemasan dan insomnia, di mana stres dan kecemasan adalah predisposisi atau faktor yang memberat kelelahan yang dialami oleh pasien dengan penyakit jantung. Selain itu dengan penerapan PMR tidak ditemukan efek merugikan dari terapi tersebut.
Hasil penelitian ini didukung dan sejalan dengan penelitian judul The Effect of Music and Progressive Muscle Relaxation on Anxiety, Fatigue, and Quality of Life in Family Caregivers of Hospice Patients, menggunakan PMRT sebagai relaxation therapy, membuktikan bahwa terapi relaksasi dapat meningkatkan kondisi psikologis, dan kesejahteraan klien (Choi, 2010). PMR secara langsung menimbulkan rasa kedamaian kepada pasien dan mengurangi masalah irasional mereka pikiran yang dapat menyebabkan depresi yang nantinya akan berdampak pada kondisi vaskuler dan tekanan darah. Ketika otot yang ada di dalam tubuh menjadi rileks, maka akan terjadi vasodilatasi pada pembuluh darah yang mengakibatkan sirkulasi darah menuju jaringan akan lancar. Proses sirkulasi ini akan membawa oksigen serta nutrisi ke jaringan secara adekuat. Jaringan yang mendapatkan pasokan oksigen dan nutrisi yang adekuat dapat melangsungkan proses metabolisme sehingga akan menghasilkan energi yang cukup bagi aktivitas yang akan dilakukan ((Hasanpour-Dehkordi \& Jalali, 2016; Ozgundondu \& Gok Metin, 2019).

Teknik ini berdasarkan teori bahwa proses berpikir berhubungan dengan kondisi otot, di dalam prosedur PMRT klien mengarahkan seseorang untuk tenang dalam memikirkan sesuatu hal yang lebih besar dan memecahkan masalah emosional. Menurut Mantle and Tiran (2010) evidence yang mendukung peran PMRT diantarnya dalam mengurangi stres, kecemasan dan insomnia, di mana stres dan kecemasan adalah predisposisi atau faktor yang memberatkan, dan tidak ditemukan efek merugikan dari terapi tersebut. Teknik yang dilakukan yaitu dengan menegangkan otot kemudian merelaksasikannya kembali, dan membantu klien dalam menangani situasi stress jangka pendek. Kondisi 
stres tersebut terjadi karena peningkatan respon dari saraf simpatis, maka akan memunculkan tanda seperti dilatasi pupil, napas dangkal, peningkatan denyut jantung, dan ketegangan pada otot (Snyder \& Lindquist, 2012).

Hasil penelitian juga diperkuat dengan pembuktian yang telah dilakukan oleh $\mathrm{Yu}$ et al (2010) dengan artikelnya yang berjudul : Improving health-related quality of life of patient with chronic heart failure: effects of relaxation therapy (Yu et al, 2010) dengan menggunakan desain Randomized Kontrol Trial (RCT) dengan desain pendekatan experiment, pretest-postest with kontrol group dan dilakukan pada pasien dengan diagnosa Congestif Heart Failure dengan functional class NYHA IIIII membuktikan efektivitas PMR dalam menurunkan level fatigue. Hal ini menunjukkan bahwa berdasar hasil penelitian dan dukungan dari bukti hasil penelitian selanjutnya dapat disimpulkan bahwa terapi Progressive Muscle Ralxation merupaan suatu penatalaksanaan yang tepat diberikan bagi pasien dengan penyakit jantung untuk mengatasi masalah fatigue nya.

\section{Simpulan dan Saran}

Upaya kesehatan dalam hal ini adalah manajemen perawatan diri pada penderita penyakit jantung saat ini dapat dikatakan yang terpenting adalah upaya dalam hal faktor fisik dan psikis. Penanganan secara fisik melaui obatobatan untuk mencegah gejala yang timbul sudah biasa dilakukan namun kenyataan nya masih muncul gejala yang tidak diinginkan salah satunya adalah kelelahan atau fatigue yang akan mempengaruhi kualitas hidupnya.

Hasil penelitian ini menunjukkan bahwa progressive muscle relaxation efektif untuk mengatasi masalah fatigue pada penderita gagal jantung. Penelitian ini membuktikan bahwa penanganan bagi penderita penyakit gagal jantung khususnya dalam mengaatasi masalah gangguan aktivitas perlua dilakukan suatu terapi aktivitas dengan pendekatan fisik dan emosional salah satunya adalah progressive muscle relaxation. Saran bagi peneliti selanjutnya perlu dikembangkan metode dengan dengan pendekatan fisik (PMR) dan emosional (psikis) untuk meningkatkan kapasitas fisik bagi penderita gagal jantung.

\section{Referensi}

Black, Joyce M. \& Hawks. (2014). Medical-Surgical Nursing Clinical Management for Positives Outcomes ( $8^{\text {th }} E d$.). Singapore: Elseiver (Singapore) Pte Ltd

Bromage, D. I., Cannatà, A., Rind, I. A., Gregorio, C., Piper, S., Shah, A. M., \& McDonagh, T. A. (2020). The impact of COVID-19 on heart failure hospitalization and management: report from a Heart Failure Unit in London during the peak of the pandemic. European Journal of Heart Failure, 22(6), 978-984. https://doi.org/10.1002/ejhf.1925

Brown, J. P., Clark, A. M., Dalal, H., Welch, K., \& Taylor, R. S. (2011). Patient education in the management of coronary heart disease, (12). retrieved from https://doi.org/10.1002/14651858. CD008895.pub2

Bunyamin, V., Spaderna, H., \& Weidner, G. (2013). Health behaviors contribute to quality of life in patients with advanced heart failure independent of psychological and medical patient characteristics. Quality of Life Research: An International Journal of Quality of Life Aspects of Treatment, Care and Rehabilitation, 22(7), 1603-11. https://doi.org/10.1007/s11136012-0312-6

Care, C. N. (2016). Effect of Benson 
Relaxation on Fatigue of Nurses Working in Intensive Care Units, 1(4), 211-217.

Choi, Y. K. (2010). The Effect of Music and Progressive Muscle Relaxation on Anxiety, Fatigue, and Quality of Life in Family Caregivers of Hospice Patients, (1), 53-69.18(10), 983987. retrieved from https://doi.org/10.1089/acm.2011. 0390

DeFilippis, E. M., Reza, N., Donald, E., Givertz, M. M., Lindenfeld, J. A., \& Jessup, M. (2020). Considerations for Heart Failure Care During the COVID-19 Pandemic. JACC: Heart Failure, 8(8), 681-691. https://doi.org/10.1016/j.jchf.2020. 05.006

Garin, O., Herdman, M., Vilagut, G., Ferrer, M., Ribera, A., Rajmil, L., ... Alonso, J. (2014). Assessing health-related quality of life in patients with heart failure: a systematic, standardized comparison of available measures. Heart Failure Reviews, 19(3), 359367. retrieved from https://doi.org/10.1007/s10741013-9394-7

Hasanpour-Dehkordi, A., \& Jalali, A. (2016). Effect of progressive muscle relaxation on the fatigue and quality of life among iranian aging persons. Acta Medica Iranica, 54(7), 430-436.

Hines, P. A. (2010). Preventing Heart Failure Readmissions: Is Your Organization Prepared?, 28(2), 7487.

James,K.R.,Theodore,A.S.,Kathy, A.H.,Dominique, L.M.2013. Diagnosis and Treatment of Depression in Patient With Congestive Heart Failure: A Review of the Literature.A publication of The Primary Care Companion For CNS disorders. Vol 15(4).
Kessing, Dionne. (2015). Fatigue and Self-Care in Patients with Chronic Heart Failure. Journal of Cardiovascular Nursing 29.https://pubmed.ncbi.nlm.nih.gov/ 25715645/. Diperoleh tanggal 8 Juni 2020.

Ozgundondu, B., \& Gok Metin, Z. (2019). Effects of progressive muscle relaxation combined with music on stress, fatigue, and coping styles among intensive care nurses. Intensive and Critical Care Nursing, 54 , 54-63. https://doi.org/10.1016/j.iccn.2019 .07 .007

Reza, N., DeFilippis, E. M., \& Jessup, M. (2020). Secondary impact of the COVID-19 pandemic on patients with heart failure. Circulation: Heart Failure, 13(5), 11-13. https://doi.org/10.1161/CIRCHEAR TFAILURE.120.007219

Sulastini, Ratnasari, Devi ., Nugraha, Andri., Ramdani, Hasbi Taobah \& Nugraha, Bambang Aditya. (2020). Peningkatan Kapasitas Keluarga Dalam Perawatan Aktifitas SehariHari Pasien Gagal Jantung. Jurnal Pengabdian Masyarakat 1(2):52-56. http://jkd,stikesdrigahayusamarind a.ac.id/index.php/jpmk/article/dow nload/124/53. Diperoleh tanggal 02 Maret 2020.

Sulistyo, Endar. (2018). Hubungan Dukungan Keluarga Dengan Kualitas Hidup Pasien Gagal Jantung Kongestif Di Poliklinik Jantung RSUD Kabupaten Sukoharjo. Jurnal Ilmu Keperawatan. Eprints.ums.ac.id/59325/ Diperoleh tanggal 19 Oktober 2019.

Udjianti, Wajan Juni (2013). Keperawatan Kardiovaskuler. Jakarta: Salemba Medika. 